\title{
UMA ANÁLISE COMPARATIVA DOS REFLEXOS DA REESTRUTURAÇÃO DO CURRÍCULO DA EDUCAÇÃO DE JOVENS E ADULTOS DO COLÉGIO DE APLICAÇÃO JOÃO XXIII ENTRE OS ANOS DE 2012 A 2016
}

\author{
Fausto Daniel Alves Fernandes ${ }^{1}$ \\ Sheila Cristina Gonçalves ${ }^{2}$
}

\section{Resumo}

Pretende-sediscutir no presenteartigoalgumas decorrências dastransformações curriculares da Educação de Jovens e Adultos (EJA) ofertada pelo Colégio de Aplicação João XXIII da Universidade Federal de Juiz de Fora (UFJF) entre os anos de 2012 a 2016. Discutir um modelo de EJA que mantenha a coerência entre o discurso e a prática tem se revelado um desafio que este colégio se propôs a encarar. Nesse processo houve mudanças curriculares, dentre as quais podemos citar a que ocorreu em 2013, que foi analisada por Fernandes e Gonçalves (2015), possibilitando enxergar que a mudança ocorreu em uma conjuntura em que a oferta de vagas foi ampliada, neste contexto a reforma curricular possibilitou uma redução na reprovação e na taxa de evasão, além de um aumento na nota média atingida pelos aprovados. A metodologia utilizada foi por meio de pesquisas bibliográficas, na via de debater a problemática que envolve o conceito do tema proposto, bem como por levantamento e cruzamento do banco de dados da modalidade EJA do colégio de Aplicação João XXIII- UFJF.

Palavras- chave: Reestruturação, educação, currículo

\section{A COMPARATIVE ANALYSIS OF REFLECTIONS OF THE RESTRUCTURING \\ OF THE CURRICULUM OF EDUCATION OF YOUTH AND ADULTS OF THE COLLEGE OF APPLICATION JOHN XXIII BETWEEN THE YEARS OF 2012 TO 2016}

\section{Abstract}

In this article we intend to discuss some of the consequences of the curricular

\footnotetext{
${ }^{1}$ Graduado matemática -UFJF, mestrando matemática -UFJF

2 Graduada em Ciências Sociais -UFJF, Especialista em política da promoção da igualdade racial na escola-UNIAFRO-UFOP, especialista em planejamento, implementação e gestão da EAD-UFF, mestranda em Ciências Sociais-UFJ- leysha_mg@yahoo.com.br
} 
transformations of Youth and Adult Education (YAE) offered by the John XXIII Application College of the Federal University of Juiz de Fora (UFJF) between the years 2012 to 2016. Discuss a model of EJA that maintains the coherence between discourse and practice has been a challenge that this college has set out to face. In this process there were curricular changes, among which we can cite the one that occurred in 2013, which was analyzed by Fernandes and Gonçalves (2015), making it possible to see that the change took place in a context in which the vacancies were expanded, in this context the reform Curricula allowed for a reduction in failure and dropout rate, in addition to an increase in the average grade reached by those approved. The methodology used was through bibliographical research, in the way of discussing the problematic that involves the concept of the proposed theme, as well as by surveying and crossing the database of the modality EJA of the college of Application John XXIII.-UFJF.

Keywords: Restructuring, education, curriculum

\section{Introdução}

A EJA, vem sendo compreendida pelo Estado como modalidade de ensino voltada para inclusão de jovens que não conseguiram concluir seus estudos na idade preestabelecida pelo sistema de ensino. O Parecer do Conselho Nacional de Educação CNE/Câmara de Educação Básica-CEB 11/2000, demarcou que essa modalidade de ensino possui três importantes funções reparadoras, visto que seu público não teve acesso a uma adequada correlação entre "idade própria/ ano escolar" ou por inúmeros motivos não tiveram acesso à escolarização. Equalizadora, pois dá cobertura a diversos segmentos sociais estendendo seu papel de troca de experiências nesse processo, deixando de ser apenas transmissor de conhecimento. Qualificadora, pois essa modalidade procura oferecer oportunidade para seus estudantes se qualificarem.

Existem várias motivações que levam um jovem ou um adulto ao retorno escolar, mercado de trabalho, a própria necessidade de resgate da socialização, sensação de dignidade, recuperação do tempo perdido, dentre outas motivações. Por esses motivos torna-se importante que o professor trabalhe esse resgate educacional junto aos alunos bem como o saber local do aluno, aquele que não é valorizado no meio acadêmico. Os jovens e adultos que abandonaram a vida acadêmica ao retornarem a escola, buscam participar da sociedade letrada da qual foram excluídos por não dominarem determinados aspectos da leitura e escrita (STRELHOW, 2010). 
A Lei n 9.394/96, de 20 de dezembro de 1996, Lei Diretrizes e Bases da Educação Nacional (LDB), colaborou para o estabelecimento da "Educação de Jovens e Adultos como modalidade de ensino através da resolução CNB/CEB $N^{0}$ 1, de 5 de julho de 2000, que estabelece as Diretrizes Curriculares Nacionais para a Educação de Jovens e Adultos" (STRELHOW, 2010 p.7). A estruturação do currículo da EJA fica sobre a responsabilidade da escola, que por sua vez deve se atentar às necessidades de sua comunidade, conforme orienta a legislação, bem como pela manutenção da carga horária que não pode perder suas características básicas.

A metodologia utilizada por Fernandes e Gonçalves (2015) para a análise da reestruturação da EJA do ano de 2013 foi por meio de pesquisas bibliográficas, na via de debater a problemática que envolve o conceito do tema proposto, bem como por levantamento e cruzamento do banco de dados da modalidade EJA do colégio de Aplicação João XXIII- UFJF. O presente estudo utilizou a mesma metodologia com a finalidade de alcançar plenitude da comparação dos dados colhidos no ano de 2015 por Fernandes e Gonçalves (2015) com os dados colhidos no ano de 2016. Além disso, a estratégia metodológica principal da proposta apresentada foi de caráter quantitativo, almejando criar um panorama geral comparativo da situação do alunato da instituição supracitada. Intentou-se, portanto elaborar gráficos e fluxogramas como instrumentos de análise capazes de trazer à tona alguns elementos, tais como, a evolução numérica e percentual de alunos, principalmente quanto aos abandonos ao longo do curso.

\section{Breve contexto histórico da Educação de Jovens e adultos no Brasil}

No período colonial a educação era direcionada as crianças, mas indígenas adultos também foram submetidos à educação dos missionários da Companhia Missionária de Jesus, que tinham como um das suas funções ensinar a língua portuguesa para os indígenas que viviam na colônia com a finalidade de catequizálos (STRELHOW, 2010).

Os missionários da Companhia Missionária de Jesus deixaram o Brasil no ano de 1759, a educação brasileira entrou em colapso. A educação ficou a cargo do Império que assumiu a responsabilidade pela reestruturação da educação. Entre as mudanças, estava a centralização da educação para jovens e adultos especificamente para herdeiros (homens brancos) dos colonizadores, ficando excluídos do processo educacional, as mulheres, os pobres, os negros e indígenas 
(STRELHOW, 2010). Demarcando a desigualdade de oportunidade educacional de gênero, classe e raça no Brasil.

No ano de 1827, a educação foi novamente reestruturada, A constituição Imperial de 1827 garantiu por meio do ato constitucional a educação primária a todos os cidadãos, em especial jovens e adultos (Lei de 15 de Outubro de 1827) porém essa lei não saiu do papel. As camada mais pobres não foram favorecidas, a preocupação da elite da época implicava nos gastos que viriam com a inclusão educional de negros e negras livres, negras e negros escravos, mulheres e homens pobres.

Em 1834 o ato constitucional, garantiu a educação primária e secundária a todos os cidadãos, em especial jovens e adultos. A educação primária e secundária ficou sobre responsabilidade das províncias. As instruções dos pauperizados ainda possuíam o viés de um ato de caridade. As pessoas analfabetas eram estigmatizadas com características infantis ou de incapaz. As pessoas letradas tinham missão de ensinar os ignorantes com a finalidade de promover o progresso da sociedade (STRELHOW, 2010). Essas pessoas por não saberem ler e escrever eram excluídas do processo eleitoral e ficavam à margem da sociedade.

Entre os anos de 1879 e 1882, os analfabetos foram considerados como ignorantes e foram caracterizados como infantilizados, por conta dessa situação eram impedidos de votar. Os analfabetos eram excluídos socialmente, viviam na sociedade, mas não faziam parte dela, não podiam participar de decisões importantes, mesmo que tivessem renda ou posses havia um decreto de 1891 que impedia os analfabetos de votar (STRELHOW, 2010).

No inicio do século XX, o subdesenvolvimento do Brasil era creditado aos analfabetos. Para eliminar esse mal em 1915 foi criada a Liga Brasileira, que tinha como foco lutar contra o analfabetismo. Para os estudiosos da época, os analfabetos eram considerados um atraso para o país. Com a crise cafeeira de 1929, os investimentos voltaram-se para as indústrias, essas modificações implicaram também mudanças na educação. $O$ primeiro plano que previa a Educação de Jovens e Adultos foi lançado em 1934 e foi denominado Plano Nacional de Educação. Na década de 40 e 50, a Educação de Jovens e Adultos foi prioridade do país (STRELHOW, 2010).

Em 1947 surge o Serviço de Educação de Adultos (SEA), esse modelo de aprendizagem adotado no Brasil não levava em conta a criatividade do aluno e desestimulava a produção do seu próprio conhecimento. Sendo o discente induzido a reproduzir apenas o conteúdo transmitido pelo professor. As 
diferenças individuais bem como as dificuldades na aprendizagem não eram inseridas no plano de aula.

A década de 60 foi marcada pelas ações dos movimentos sociais voltadas para a Educação de Jovens e Adultos. Esses "movimentos procuravam reconhecer e valorizar o saber e a cultura popular, considerando assim, a pessoa não alfabetizada uma produtora de conhecimento" (STRELHOW, 2010, p.6).

Em 1964, durante o golpe militar, o governo como uma forma de controle social e homogeneização dos indivíduos criou o Movimento Brasileiro de Alfabetização (Mobral), cujo objetivo era habilitar o discente na leitura e na escrita. A aprendizagem era uma coisa distante da realidade do aluno, para o discente era necessário apenas saber copiar e depois reproduzir fielmente o que aprendeu, sem questionar a veracidade dos fatos ou compará-los a sua realidade. "Configurava-se assim, o sentido político do Mobral, que procurava responsabilizar o indivíduo de sua situação desconsiderando-o do seu papel de ser sujeito produtor de cultura" (STRELHOW, 2010, p.6).

Os instrutores do MOBRAL eram pessoascom pouca instrução pedagógica, pois para o governo militar não era necessário ser especialista para ensinar indivíduos adultos (STRELHOW, 2010). Em 1985 o MOBRAL foi extinto sob denuncias de desvio de dinheiro. Outros programas foram criados como a Fundação Educar, que tinha como finalidade supervisionar os recursos repassados as secretarias para a avaliação dos programas de alfabetização. Em 1990 a "Fundação Educar" foi extinta.

Na década de 90 o governo ficou ausente em relação à Educação de Jovens e Adultos. Os municípios assumiram essa função. Alguns movimentos surgiram nessa época como o Movimento de Alfabetização (Mova), cujo intuito era alfabetizar a partir do contexto socioeconômico do educando.

No ano de 1996, o governo criou o programa nacional de alfabetização. No Programa Alfabetização Solidária (PAS), os alfabetizadores não eram bem preparados para educar os jovens e adultos. No ano de 1996 foi sancionada lei n 9.394/96, de 20 de dezembro de 1996, Lei Diretrizes e Bases da Educação Nacional (LDB), baseada nessa lei foi estabelecida a EJA como modalidade de Ensino. Em 1998, o governo criou o Programa Nacional de Educação na Reforma Agrária (PRONERA), este programa era voltado para as áreas de assentamento (STRELHOW, 2010).

Os programas criados pelo governo para a Educação de Jovens e adultos "visavam o avanço na educação e a erradicação do analfabetismo no Brasil, 
no entanto, o nível de organização desses planos é surpreendentemente atabalhoado" (STRELHOW, 2010 p.9). Os projetos eram desfeitos e substituídos por outro antes de alcançarem o objetivo planejado.

\section{EJA no colégio de aplicação João XXIII}

No ano de 1996, foi criado um projeto experimental para o nível do Ensino Fundamental atrelado ao Plano Institucional de Desenvolvimento do Pessoal da UFJF (PLIDEP) e articulava-se com o Programa de Capacitação TécnicoAdministrativa da UFJF (PROCAT). A iniciativa foi fruto da uma parceria entre o Colégio de Aplicação João XXIII (CAJXXIII) da Universidade Federal de Juiz de Fora (UFJF) e a Pró-reitoria de Recursos Humanos da mesma universidade. A justificativa para a implementação desse projeto foi a necessidade de suprir a formação básica para os funcionários da UFJF. O projeto ainda atendia a demanda de estágios dos cursos de licenciatura da mesma universidade (Colégio de Aplicação João XXIII) ${ }^{3}$. O projeto foi denominado de Curso de Educação para Jovens E Adultos- CEJA.

No ano seguinte é implementado no CEJA o mesmo sistema de avaliação adotado no ensino regular do Colégio de Aplicação João XXIII. Em 1998 o curso é inserido no Regimento do Colégio, tornando-se formalmente mais um segmento de ensino oferecido pelo Colégio. Junto a essas mudanças ocorreu a ampliação das vagas do CEJA. As vagas foram distribuídas entre os funcionários e a comunidade. Consequentemente, em 2007, houve o primeiro sorteio público para ingresso de alunos da comunidade para o $6^{\circ}$ ano do Ensino Fundamental e $3^{\circ}$ ano do Ensino Médio. A procura pelo CEJA aumentou significativamente, devido a crescente procura pela oferta pública dessa modalidade de ensino no turno da noite, o número das vagas destinadas a comunidade foi ampliada. A quantidade de matrículas ativas no final de dois semestres consecutivos aumentou em torno de 9\% (Colégio de Aplicação João XXIII). ${ }^{4}$ Essa demanda vem aumentando a cada ano, como mostra o gráfico 1.

\footnotetext{
${ }^{3}$ As informações foram cedidas pela secretaria do Colégio de Aplicação João XXIII UFJF. ${ }^{4}$ Idem ao item anterior
} 
Evolução numérica das matrículas no Curso para Educação de Jovens e Adultos de 2010 a 2016.

\section{Gráfico 1}

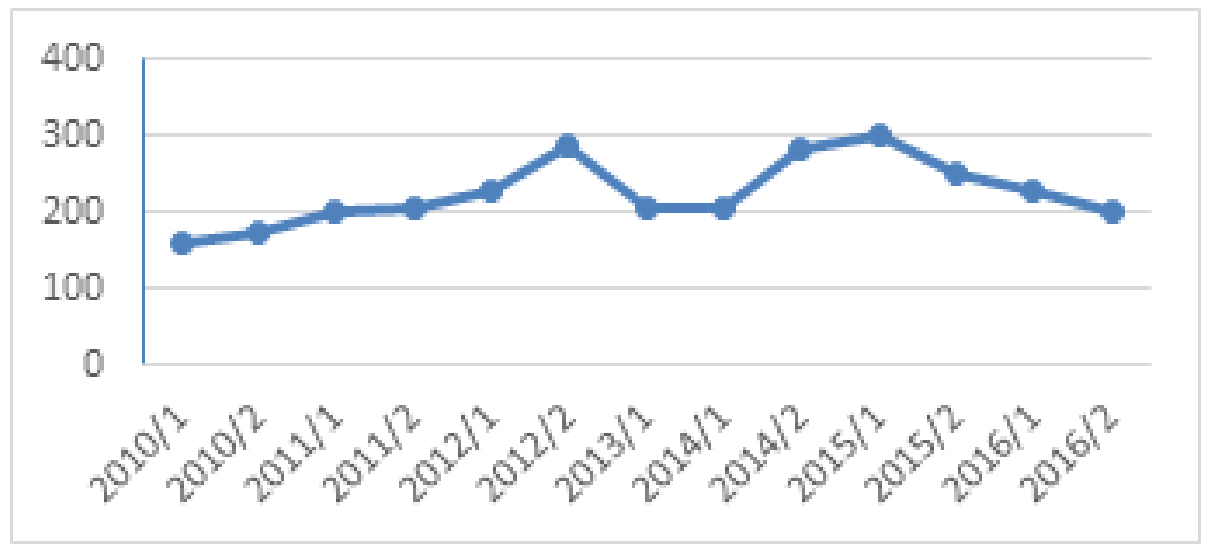

Fonte desenvolvida pelo autor

A CEJA possui atuando em sala de aula, atualmente, 34 bolsistas do Programa de Iniciação À Docência Na Educação De Jovens E Adultos Do Colégio De Aplicação João XXIII -PIDEJA, os quais são agrupados por disciplina possuindo pelo menos um professor orientador.

\section{Reestruturação do currículo da Educação de Jovens e Adultos}

O Parecer CEB/CNE n²9/2006 é reiterado pela Resolução Nº 3, de 15 de junho de 2010 quanto a regulamentação da carga horária da EJA. A carga horária mínima para os anos iniciais do Ensino Fundamental é de no mínimo dois anos entendidos como um curso de 1.600 (mil e seiscentas) horas, para os anos finais do Ensino Fundamental. E um ano e meio entendidos como um curso de 1.200 (mil e duzentas) horas para o Ensino Médio (FERNANDES E GONÇALVES, 2014). A idade para ingresso na EJA é determinada pela Resolução Nº 3, de 15 de junho de 2010. O estudante deve possuir 15 anos completos, para o ingresso nos anos finais do Ensino Fundamental e 18 anos completos para o Ensino Médio (RESOLUÇÃO No 3, DE 15 DE JUNHO DE 2010). A estrutura do currículo da EJA é deixada a cargo da escola, que deve se atentar às necessidades de sua comunidade, conforme orienta a legislação, isso sem abrir mão da carga horária mínima obrigatória. 
No ano de 2012 a EJA do colégio de aplicação João XXIII, analisou o perfil da comunidade atendida pelo colégio e buscou atender melhor os discentes com uma carga horária mais adequada, que culminou na aprovação de um novo currículo tendo por base a Proposta de Reestruturação do Curso de Educação de Jovens e Adultos. Foi elaborado um modelo pedagógico próprio com a finalidade de que seu público fosse atendido de acordo com sua realidade, possibilitando uma releitura da sociedade em que estão inseridos, bem como sua participação profissional no mercado de trabalho.

A proposta de reestruturação apresentou uma organização curricular, oferecendo 1.680 horas (dois anos e meio) para os anos finais do Ensino Fundamental e 1.320 horas (dois anos) para o Ensino Médio, ambas estavam acima do mínimo exigido por lei. Tais mudanças decorrentes dessa proposta rompem não só com a nomenclatura de séries ou anos escolares, mas também com a estrutura de pré-requisitos existentes dentro das etapas escolares, trazendo dessa forma, uma mudança na estrutura do curso (FERNANDES E GONÇALVES, 2014).

No modelo anterior a reestruturação proposta em 2012, os $6^{\circ}, 7^{\circ}, 8^{\circ}$ e $9^{\circ}$ anos escolares do Ensino Fundamental eram oferecidos em quatro semestres, com a reestruturação esse segundo ciclo do Ensino Fundamental foi substituído por cinco Períodos Fundamentais (PF) oferecidos em cinco semestres, sendo expressos pelas siglas PF1, PF2, PF3, PF4 e PF5. No modelo novo de currículo o estudante que concluiu o $5^{\circ}$ ano do Ensino Fundamental, por exemplo, cursaria os cinco períodos fundamentais na ordem que lhe fosse melhor. De forma análoga, o estudante que concluiu o Ensino Fundamental, cursaria o Ensino Médio em quatro semestres nos Períodos Médios (PM), PM1, PM2, PM3 e PM4 também em qualquer ordem (Bezerra e Sanches, 2012).

Esse modelo curricular se pauta nos chamados Períodos de Estudos Focalizados, nos quais a oferta de disciplinas focam ênfases e tópicos. As ênfases são as disciplinas que possuem mais aulas por semestre, de modo que o aluno possa concentrar seus estudos nessas disciplinas. Os tópicos são oferecidos de acordo com a realidade social de cada turma, posto que são disciplinas cujo foco é a aplicação do conhecimento escolar em problemas sociais e na vida profissional dos estudantes (Bezerra e Sanches, 2012).

Quanto ao sistema de avaliação, as mudanças foram substanciais, anteriormente o estudante para ser aprovado deveria obter aproveitamento de $50 \%$ dos pontos em todas as disciplinas, contudo se não conseguisse era 
Ihe dado uma atividade de recuperação no fim do semestre. Caso atingisse a pontuação necessária, era aprovado (Colégio de Aplicação João XXIII). ${ }^{5}$ Com a reestruturação o aluno reprovado cuja média global fosse igual a ou maior que 40 pontos, ele poderia cursar outro período escolar no semestre seguinte, mas ao final desse ele deveria fazer novo exame geral para ser aprovado naquele que ficou com pendência (Bezerra e Sanches, 2012). O fluxograma 1 ilustra a reestruturação em 2013:

Fluxograma 1

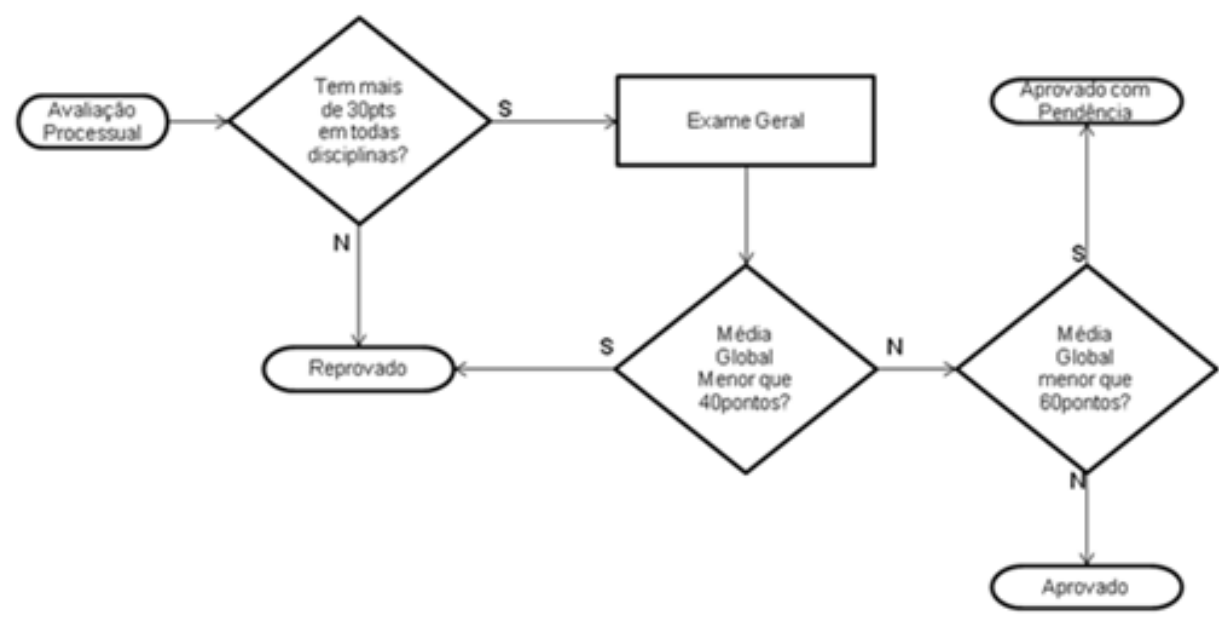

Fonte desenvolvida pelo autor 2014

O aluno concorria a 70 pontos de avaliação processual em cada disciplina, no final do semestre se atingisse no mínimo 30 pontos (dos 70 pontos distribuídos) poderia realizar o Exame Geral. Este exame tinha valor total de 30 pontos e o resultado desse era somado a pontuação já obtida em cada disciplina. O estudante que obtinha Média Global igual ou superior a 60 pontos era considerado aprovado. Esse valor era obtido por meio da média ponderada da pontuação em cada disciplina, sendo que cada uma tinha seu peso dado de forma proporcional ao número de aulas. (Bezerra e Sanches, 2012).

Em 2014, não era mais necessário atingir uma pontuação mínima na avaliação processual para se fazer o Exame Geral e consequentemente ser aprovado. No que se refere à frequência, foi mantida a exigência de pelo menos 75\% de presença para o aluno ser considerado aprovado (Colégio de Aplicação João

\footnotetext{
${ }^{5}$ Idem ao item anterior
} 
Uma análise comparativa dos reflexos da reestruturação

do currículo da EJA do CA João XXIII, pp. 227 - 241

$X X \mid I I)$.

O fluxograma 2 apresenta a reestruturação em 2014.

Fluxograma 2

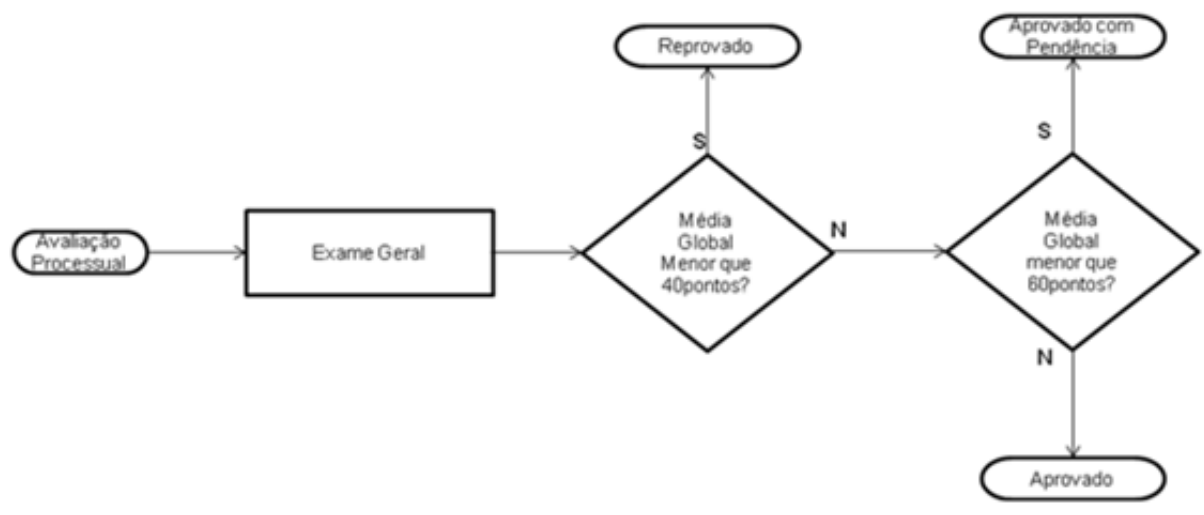

Fonte desenvolvida pelo autor 2014

A reestruturação do currículo da EJA teve sua vigência iniciada no $1^{\circ}$ semestre de 2013 e foi totalmente implantado no $1^{\circ}$ semestre de 2015 , sofrendo nesse tempo, alteração em alguns aspectos como, novas disciplinas ofertadas, bem como carga horária (a carga horária total foi mantida) das disciplinas alteradas (FERNANDES E GONÇALVES, 2014).

No ano de 2016 o currículo foi reestruturado, o antigo modelo seriado 6 ${ }^{\circ}$, $7^{\circ}, 8^{\circ}$ e $9^{\circ}$ ano do Ensino Fundamental, bem como o Ensino Médio $\left(1^{\circ}, 2^{\circ}\right.$ e $3^{\circ}$ ano) foram novamente adotados. O fluxograma 3 apresenta a restruturação do sistema de avalição do ano de 2016.

Fluxograma 3

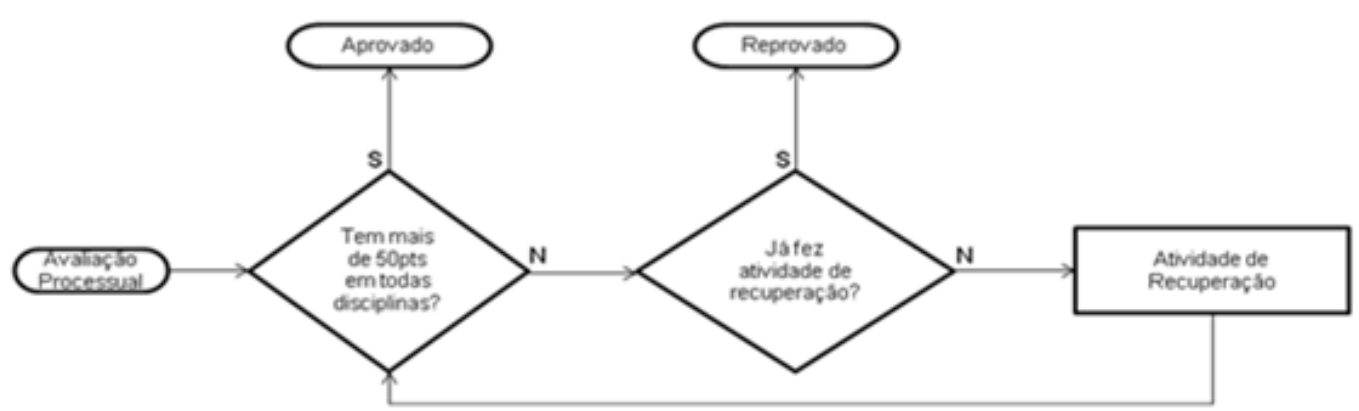

Fonte desenvolvida pelo autor 
No antigo sistema de avaliação o discente quando não atingia a pontuação mínima para ser aprovado, poderia recorrer ao exame geral como mostra o fluxograma 1, caso atingisse a média de 60 pontos seria aprovado. $O$ valor menor que 60 pontos o aluno seria aprovado com pendencia, mas havia a exigência de que o aluno tivesse no mínimo 30 pontos em todas as disciplinas. $\bigcirc$ fluxograma 2 mostra que o aluno que não atingisse a pontuação mínima também poderia realizar o exame geral. Não havia uma pontuação mínima para a realização do exame. O fluxograma 3 apresenta a reestruturação do sistema de avalição. O aluno para ser aprovado necessita de no mínimo 50 pontos em todas as disciplinas. Caso não atinja os 50 pontos em alguma das disciplinas ofertadas, necessita fazer uma prova de recuperação.

Para fins deste estudo, tomou-se por referência o segundo semestre de 2015 e o segundo de 2016 (o segundo depois da reestruturação da EJA). Partindo das informações destes períodos, foram feitas análises sobre o índice de aprovação e de abandono de curso, além de comparar as notas médias dos estudantes como mostrado a tabela 1

Tabela 1 - Comparativo de Índices Relacionado a Alunos

\begin{tabular}{c|c|c}
\hline & $2^{\circ}$ sem. de 2015 & $2^{\circ}$ sem. de 2016 \\
\hline Índice de abandono & $30 \%$ & $6 \%$ \\
\hline Índice de aprovação & $56 \%$ & $52 \%$ \\
\hline Pontuação Média & $59,71 \mathrm{pts}$ & $67,05 \mathrm{pts}$ \\
\hline
\end{tabular}

Fonte desenvolvida pelo autor

Na reestruturação da EJA o índice de abandono decresceu significativamente, como apresenta a tabela 1. No segundo semestre de 2015 (antigo currículo) o índice de abandono era de 30\% esse índice decresceu para $6 \%$ no segundo semestre de 2016 (novo currículo). Foram disponibilizadas 80 novas vaga, distribuídas entre o $6^{\circ}, 7^{\circ}, 8^{\circ}, 9^{\circ}$ ano do Ensino fundamental e $2^{\circ}$ e $3^{\circ}$ ano do Ensino Médio (Edital 002/2016)6. O índice de aprovação de um currículo para o outro teve uma diferença de 4 pontos percentuais entre os anos de 2015 e 2016.

Outros dados que permitem inferir sobre reflexos da mudança curricular da

${ }^{6}$ EDITAL No. 005/2016 disponível em: http://www.ufjf.br/joaoxxiii/2016/07/26/joao-xxiii-oferece-80vagas-para-educacao-de-jovens-e-adultos/(acessado 26 de julho de 2017) 
EJA são as proporções de alunos por professor, disciplina/turma por professor e quantidade de aulas semestrais ministradas por professor como apresenta a tabela 2:

Tabela 2 - Comparativo de Índices Relacionado a Bolsistas

\begin{tabular}{l|c|c}
\hline & $2^{\circ}$ sem. de 2015 & $2^{\circ}$ sem. de 2016 \\
\hline Bolsistas & 41 & 37 \\
\hline Média de Disciplina/Turmas por Bolsista & 2,22 & 2.32 \\
\hline Média de Aulas semestrais por Bolsista & 103.9 & 103.3 \\
\hline Média de Alunos por Bolsista & 6,05 & 5,38 \\
\hline
\end{tabular}

Fonte desenvolvida pelo autor

A nova reestruturação foi implantada no ano de 2016, visando adequar o currículo a realidade de seus discentes, desse modo podemos concluir que a reestruturação da EJA no Colégio de Aplicação João XXIII tem se pautado nesses princípios e é coerente com a legislação vigente. Além disso, houve a preocupação com a qualidade do envolvimento dos bolsistas em suas atividades da EJA. A média de alunos por bolsistas no ano de 2015 era de 6,05. No ano de 2016 essa média decresceu para 5,38.

\section{Considerações finais}

Levando em consideração que o critério de abandono do curso adotado nesta pesquisa foi de infrequência igual ou superior a 40\% das aulas totais da grade curricular, observa-se que este índice decresceu significativamente. Algumas diferenças entre os currículos podem apresentar indícios que justificam tais números, como a fácil correspondência com a grade atual com a praticada no ensino regular, não deixando de considerar que também tenha decrescido a quantidade de matrículas entre os períodos analisados em 20\%.

Quanto às notas, pode-se perceber que, embora tenha ocorrido um aumento na quantidade de disciplinas por turma, a média de notas por disciplina aumentou, o que, pela diferença numérica, pode levar a uma reflexão sobre o papel desempenhado pelo Exame Geral no currículo anterior, o qual detinha 30 dos 100 pontos distribuídos em todas as disciplinas.

Em contrapartida, o número de aprovados recuou. Tal fato deve ser estudado 
com uma maior profundidade em estudos seguintes, posto que o número de evadidos recuou consideravelmente e a média de nota dos alunos cresceu. Isto pode significar que, no momento presente temos desempenhos escolares muito discrepantes dentro de uma sala de aula. O tempo de implementação do novo currículo ainda é insuficiente para fornecer essa resposta. A implantação do novo currículo ocorreu no ano de 2016.

A EJA vem sendo objeto de estudo por diversos motivos, dentre eles esta a preocupação que tem feito profissionais que atuam nesta modalidade de ensino, pesquisadores e o poder público atentarem-se para suas particularidades. Assim, ao se atentar para A EJA, alguns dados são levados em consideração para que intervenções sejam feitas a fim de traçar caminhos que levem trabalhadores e estudantes que não estão cursando o ano escolar correspondente a sua idade a inserção no processo educativo. Dentre estes dados são elencados: quantidade de matriculados, percentual de evasão e aproveitamento médio nas disciplinas. Ainda assim, tem-se por certo que apenas esses dados não conseguem exprimir as particularidades guardadas na EJA, até mesmo pelo fato dos dados revelarem a necessidade de um maior aprofundamento de estudos qualitativos para sua compreensão. O tempo de implementação da reestruturação do currículo ainda não é suficiente para verificar as causas das mudanças relacionadas à evasão e reprovação dos discentes. Com o atual currículo, a evasão decresceu de 30\% para 6\%, ao mesmo tempo em que o índice de reprovação subiu de 44\% para $48 \%$, isto é, 14\% (14\% reprovados e 30\% evadidos) para 42\% (42\% reprovados e 6\% evadidos).

Mediante a esse fato, acredita-se que para melhor compreender tal realidade é necessário mergulhar mais fundo por meios qualitativos, obter novos dados que elucidem o direcionamento dado pelo atual currículo da EJA nesta instituição de ensino, posto que, as informações extraídas quantitativamente se mostram limitadas para que se constitua um quadro com um grau de proximidade satisfatória da realidade.

É importante ressaltar o dinamismo e agilidade com que os processos de mudanças ocorrem nesta modalidade de ensino, dado que seu público, cada vez mais, tem urgência por mudanças e que a escola (pedagógica e administrativamente) encontrar-se cada vez mais próxima de seus estudantes. O que no caso específico de análises na EJA do Colégio de Aplicação João XXIII, proporciona um ambiente rico e propício a pesquisas, isto por consentir que, a partir dos dados aqui expostos, ainda há muito a se investigar no sentido 
de mapear os resultados das mudanças curriculares da EJA. Investigações que, podem partir de análises estatísticas, mas em que os alunos, professores, pedagogos e a equipe administrativa sejam ouvidos a fim de complementarem ou até mesmo trazerem novos dados que os números não são capazes de exprimir.

\section{Referência}

BEZERRA, Carolina dos Santos, SANCHES, Janaina Garcia. Proposta para Reestruturação do Curso de Educação de Jovens e Adultos do Colégio de Aplicação João XXIII/UFJF 2012.

BRASIL. Decreto n 15, de 1839 Lei n. 1, de 1837, Instrução Primária no Rio de Janeiro. Disponível em http://seer.ufrgs.br/asphe/article/viewFile/29135/pdf (acessado em 22 de julho de 2015 as 17:06).

Lei de 15 de outubro de 1827. Coleção de Leis do Império do Brasil, v. 1, 15 out. 1827. p. 71. Disponível em: < http://www.histedbr.fe.unicamp.br/revista/ edicoes/38/art05_38.pdf> Acesso em: 12 abr. 2017.

FERNANDES, Fausto Daniel Alves; GONÇALVES, Sheila Cristina. Reflexos da Implantação da Proposta para Reestruturação da Educação de Jovens Adultos do Colégio e Aplicação João XXIII. In: $4^{a}$ JORNADA DE CIÊNCIAS SOCIAIS UFJF- CAMINHOS E INTERSEÇÕES, ISSN 2358-5285, 2015, Juiz de Fora-MG. Anais. Juiz de Fora-MG. 2015. p. 502-513. Disponível em: <http:// media.wix.com/ugd/5a29af_2847a677408e4f4caac223cbeebf461e.pdf> Acesso em: 25 mai. 217.

PARECER CNE /CEB ñ: 11/2000, de 10 de Maio de 2000. Diretrizes Curriculares Nacionais para a Educação de Jovens e Adultos, 2000. Disponível em Link do acesso (acessado em 22 de julho de 2015 as 16:05)

PARECER CNE/CEB No: 23/2008, de 08 de Outubro de 2008. Institui Diretrizes Operacionais para a Educação de Jovens e Adultos - EJA nos aspectos relativos à duração dos cursos e idade mínima para ingresso nos cursos de EJA; idade mínima e certificação nos exames de EJA; e Educação de Jovens e Adultos desenvolvida por meio da Educação a Distância, 2008. Disponível em Link do acesso (acessado em 23 de julho de 2015 as 17:10). 
Uma análise comparativa dos reflexos da reestruturação

do currículo da EJA do CA João XXIII, pp. 227 - 241

PARECER N.: CNE/CEB 36/2004, de 7 de Dezembro de 2004. Aprecia a Indicação CNE/CEB 3/2004, que propõe a reformulação da Resolução CNE/ CEB 1/2000, que define Diretrizes Curriculares Nacionais para a Educação de Jovens e Adultos, 2004. Disponível em Link do acesso (acessado em 23 de julho de 2015 as 16:07).

RESOLUÇÃO No 3, DE 15 DE JUNHO DE 2010. nstitui Diretrizes Operacionais para a Educação de Jovens e Adultos nos aspectos relativos à duração dos cursos e idade mínima para ingresso nos cursos de EJA; idade mínima e certificação nos exames de EJA; e Educação de Jovens e Adultos desenvolvida por meio da Educação a Distância.http://confinteabrasilmais6.mec.gov.br/images/ documentos/resolucao032010cne.pdf

STRELHOW Thyeles Borcarte. Revista HISTEDBR On-line, Campinas, n.38, p. 49-59, jun.2010 - ISSN: 1676-2584. 